\title{
Hydration degree development of blast furnace slag blended cement pastes using thermogravimetric Analysis (TGA)
}

\author{
Walid Deboucha ${ }^{1, *}$, Nordine Leklou ${ }^{1}$, and Abdelhafid Khelidj ${ }^{1}$ \\ ${ }^{I}$ LUNAM University, University of Nantes - IUT Saint-Nazaire, GeM, CNRS UMR 6183, Research \\ Institute in Civil Engineering and Mechanics, France.
}

\begin{abstract}
The hydration degree assessment of slag blended cement pastes with three different replacement levels $(10,20$ and 40\%) and two finenesses (400 and $500 \mathrm{~m}^{2} / \mathrm{kg}$ ) was investigated. The hydration degree was evaluated by using a modified TG method suggested by Deboucha et al., 2017. This method builds on the activity coefficient concept, which makes it possible to assume the amount of mineral additives that contribute to hydration reactions as well as cement. Results showed that the efficiency of blast furnace slag in developing hydration degree was conditioned by its level of replacement and fineness.
\end{abstract}

\section{Introduction}

Mineral additives are alternative materials, which are widely used as partial cement replacement with the attention of reducing the environmental impact of the cement production $[1,2,3]$. In addition to the hydration reactions of clinker phases, the presence of mineral additives have an influence on the hydration reactions of these phases due to their chemical and physical effects [4-5]. Hence, seeking ways to understand the impact of mineral additives on hydration reactions needs to be investigated.

The impact of slag on the hydration reactions of blended cement pastes is the focus of the present study. Two techniques were used to study the hydration of these systems. An isothermal calorimeter was used to quantify the influence of slag addition on hydration reactions at early ages. When we reached advanced times, thermogravimetric analysis (TGA) was used. Based on results obtained with this technique, a modified TG method suggested in previous article [6] was applied to quantify the impact of slag on hydration reactions of blended cement pastes, by measuring their hydration degree development. This method relies on the activity coefficient $\mathrm{K}$ concept, which allows to assume the amount of mineral additives that contribute to hydration reactions and then inferring the hydration degree.

\footnotetext{
*Corresponding author: walid.deboucha@univ-nantes.fr
} 


\section{Experimental program}

\subsection{Materials and mix design}

Ordinary Portland cement type I 52.5 N conforming to NF EN 197-1 [7] was used in this study. Slag (BFS) with two different degree of fineness $\left(400\right.$ and $500 \mathrm{~m}^{2} / \mathrm{kg}$ ) was used as partial cement replacement. Table 1 presents the chemical compositions of cement and slag, which were provided in previous study [8]. Fig.1 provides the particle size distribution of cement and blast furnace slag using Laser diffraction (CILAS 1180L apparatus).

Table 1. Chemical composition and physical characteristics of materials [8].

\begin{tabular}{|c|c|c|}
\hline Chemical composition (\%) & OPC & BFS \\
\hline $\mathrm{SiO} 2$ & 20.07 & 40.00 \\
\hline $\mathrm{Al2O} 3$ & 4.86 & 7.35 \\
\hline $\mathrm{Fe} 2 \mathrm{O} 3$ & 3.07 & 2.28 \\
\hline $\mathrm{CaO}$ & 64.25 & 42.69 \\
\hline $\mathrm{MgO}$ & 0.95 & 5.19 \\
\hline $\mathrm{So3}$ & 3.55 & 1.24 \\
\hline $\mathrm{K} 2 \mathrm{O}$ & 1.00 & 0.74 \\
\hline $\mathrm{Na} 2 \mathrm{O}$ & 0.18 & 0.04 \\
\hline $\mathrm{LOI}$ & 1.09 & 0.25 \\
\hline Physical characteristics & 3.14 & 2.98 \\
\hline Specific gravity & 440 & $400 / 500$ \\
\hline Blaine $\left(\mathrm{m}^{2} / \mathrm{kg}\right)$ & \multicolumn{2}{|l}{} \\
\hline \multicolumn{2}{|l|}{}
\end{tabular}

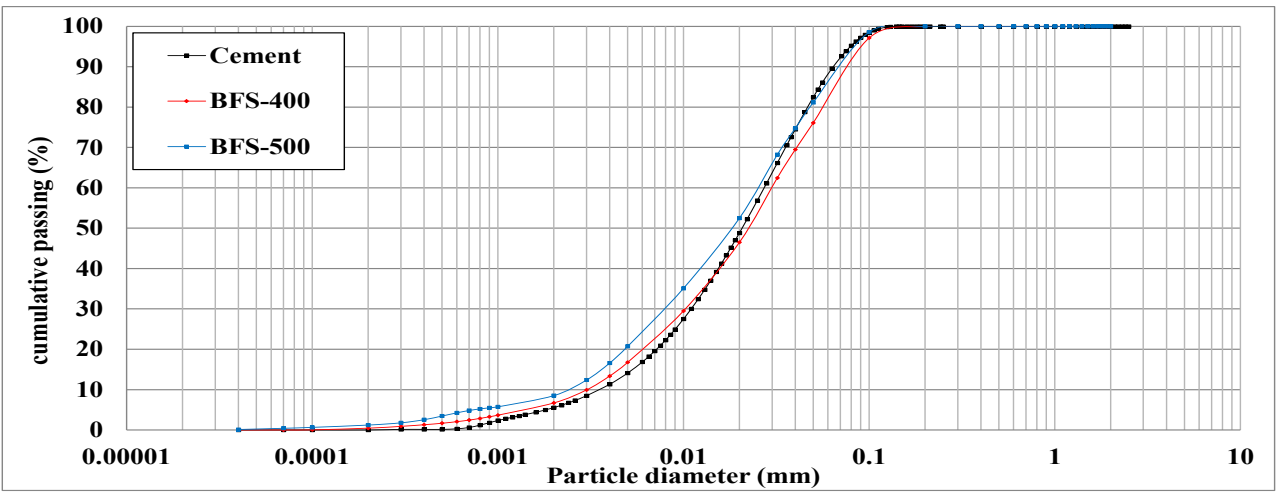

Fig. 1. Particle size distribution of slag and cement [8].

Cement pastes were prepared according to the procedure for mortar preparation, given by European standard EN NF 196-1 [9]. The Portland cement was replaced by slag with three replacement levels $(10,20$ and $40 \%)$. the water to binder ratio was selected at 0.35 . the mix proportions of the combination of cement and slag are shown in Table 2.

Table 2. Mix proportions

\begin{tabular}{|c|c|c|c|c|}
\hline mix & $\begin{array}{c}\text { Cement } \\
(\%)\end{array}$ & $\begin{array}{c}\text { BFS } \\
(\%)\end{array}$ & $\begin{array}{c}\text { Slag Fineness } \\
\left(\mathrm{m}^{2} / \mathrm{kg}\right)\end{array}$ & $\begin{array}{c}\mathrm{w} / \mathrm{b} \\
(\%)\end{array}$ \\
\hline PR & 100 & $/$ & $/$ & 0.35 \\
\hline P10BFS400 & 90 & 10 & 400 & 0.35 \\
\hline P20BFS400 & 80 & 20 & 400 & 0.35 \\
\hline P40BFS400 & 60 & 40 & 400 & 0.35 \\
\hline P10BFS500 & 90 & 10 & 500 & 0.35 \\
\hline
\end{tabular}




\begin{tabular}{|l|l|l|l|l|}
\hline P20BFS500 & 80 & 20 & 500 & 0.35 \\
\hline P40BFS500 & 60 & 40 & 500 & 0.35 \\
\hline
\end{tabular}

\subsection{Methods}

\subsubsection{Isothermal calorimeter}

The measurement of the released heat from the hydration reactions is widely used to quantify the hydration kinetics at early and very early ages. In this study, a multi-channel isothermal calorimeter TAM AIR device was used. After the end of mixing, two samples with weight of approximately $6 \mathrm{~g}$ were extracted from the mixture and placed into standard plastic vials. The plastic vials were then loaded into isothermal calorimeter. The hydration heat was measured continuously for 88 hours at a constant temperature of $20^{\circ} \mathrm{C}$.

\subsubsection{Thermogravimetric analysis}

The thermogravimetric analysis tests were carried out using a METTLER TOLEDO TGA/DSC1 with a balance accurate to $0.1 \mu \mathrm{g}$. The dynamic heating ramp varied between 25 and $1025^{\circ} \mathrm{C}$ at a rate of $5^{\circ} \mathrm{C} / \mathrm{min}$. Tests were carried out under nitrogen atmosphere on 20 $30 \mathrm{mg}$ samples cured at $20{ }^{\circ} \mathrm{C}$. The degree of hydration was determined from the thermogravimetric analysis data using a modified TG method. Equation (1) describes the methodology suggested for determining the chemically bound water $\left(\mathrm{W}_{\mathrm{B}}\right)$.

$$
W B=L d h+L d x+0.4(L d c-L d c a)-(m c \times L O I C C+m A \times L O I A C)+m_{d}
$$

where Ldh, Ldx, Ldc, Ldca, LOICC, LOIAC, $\mathrm{m}_{\mathrm{c}}, \mathrm{m}_{\mathrm{A}}$ and $\mathrm{m}_{\mathrm{d}}$ are parameters defined in ref. [6].

The hydration degree for cement pastes was estimated according to Equation (2).

$$
\alpha=W_{B} / W_{B \infty} \times L_{e q}
$$

where Leq $=\mathrm{m}_{\mathrm{C}},+\mathrm{K} \times \mathrm{m}_{\mathrm{A}}$ and $\mathrm{K}$ is the activity coefficient (the activity coefficient for slag, given by NF P 18-305 Standard is 0.9).

\section{Results and discussion}

\subsection{Cumulative heat released}

The heat released due to the chemical reactions can give an overview of the impact of mineral additives on hydration kinetics at early and very early ages. The cumulative heat released was measured continuously for $88 \mathrm{~h}$ at $20^{\circ} \mathrm{C}$ using a multi-channel isothermal calorimeter as described earlier. It was observed from Fig. 2 and 3 that the cumulative heat released for all cement pastes prepared with slag was lower than that of pure cement paste. The cumulative heat released decreased with the increase of slag content. Indeed, after $88 \mathrm{~h}$ of hydration, the cumulative heat released of cement paste containing $40 \%$ of slag with a fineness degree of $400 \mathrm{~m}^{2} / \mathrm{kg}$ was almost $23 \%$ lower than that of cement paste containing 10 $\%$ of slag with a fineness degree of $400 \mathrm{~m}^{2} / \mathrm{kg}$. This phenomenon is directly due to the dilution effect [10] and the latent hydration processes of slag [8-11]. 
With the increase of the fineness degree of slag from 400 to $500 \mathrm{~m}^{2} / \mathrm{kg}$, the cumulative heat released was slightly increased. For example, for cement paste prepared with $40 \%$ of slag, the increase of the fineness degree of slag from 400 to $500 \mathrm{~m}^{2} / \mathrm{kg}$ increased the cumulative heat released by about $4 \%$. The increase of fineness degree of mineral additive in fact can accelerate and stimulate the cement particles hydration since; the physical effect of mineral additives in cementitious systems is due to its surface area [4-12]. In this study, the increase in the cumulative heat released was found to be very low when the fineness degree of slag increased from 400 to $500 \mathrm{~m}^{2} / \mathrm{kg}$. This can be explained by the convergence of fineness for slag and cement.

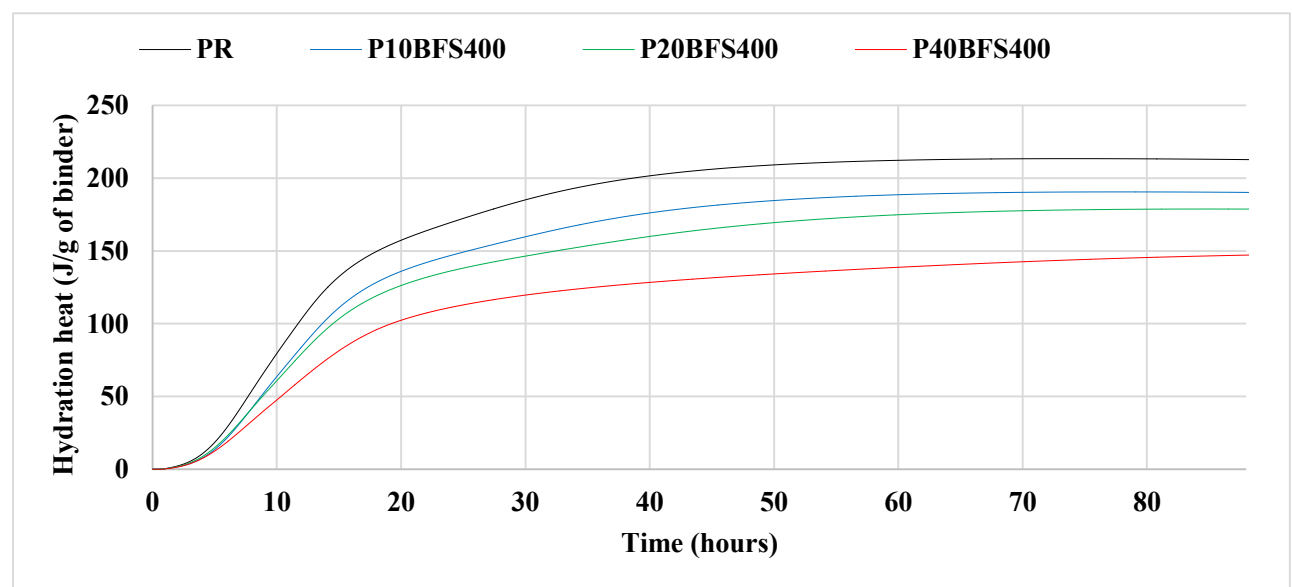

Fig. 2. Cumulative heat released for cement pastes containing BFS with fineness degree of $400 \mathrm{~m}^{2} / \mathrm{kg}$.

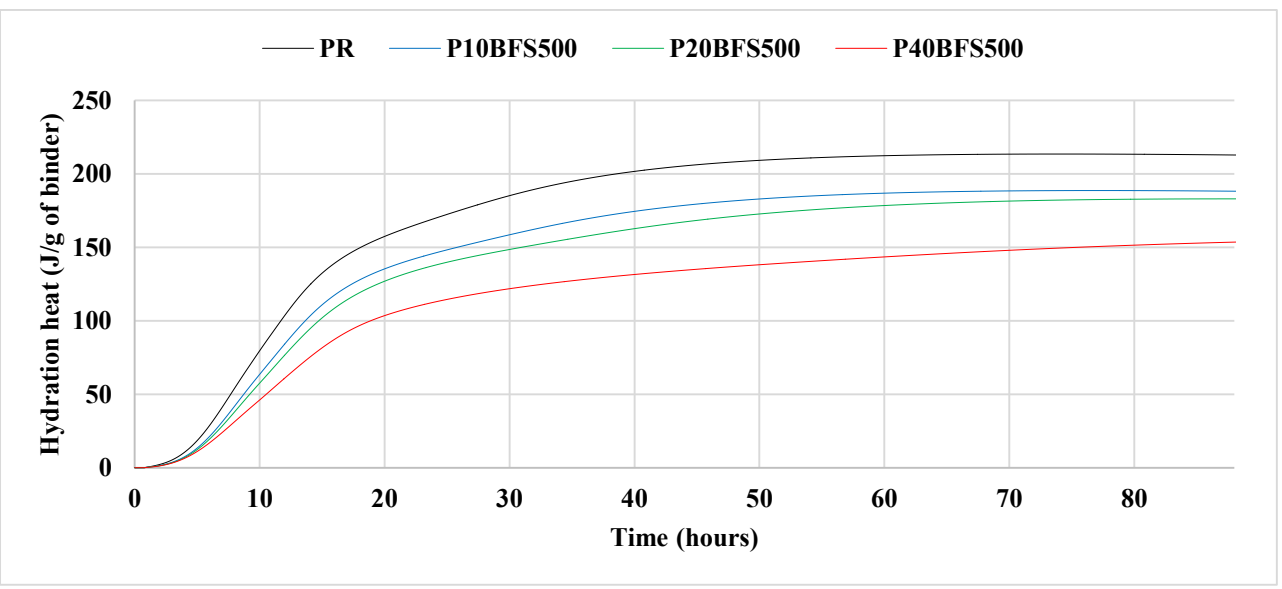

Fig. 3. Cumulative heat released for cement pastes containing BFS with fineness degree of $500 \mathrm{~m}^{2} / \mathrm{kg}$.

\subsection{Degree of hydration}

The degree of hydration of blended cement pastes containing slag with two finenesses degree of 400 and $500 \mathrm{~m}^{2} / \mathrm{kg}$ was determined using a modified TG method. The mass loss between 105 and $1000{ }^{\circ} \mathrm{C}$ was considered to determine the chemically bound water as recommended by Scrivener et al. [13]. The hydration degree was calculated according to Equation (2).

The hydration degree of the pure cement paste and cement pastes containing slag with a fineness degree of $400 \mathrm{~m}^{2} / \mathrm{kg}$ up to 90 days is shown in Fig.4. The pure cement paste showed 
higher degree of hydration at all tested ages. The contribution of slag with a fineness degree of $400 \mathrm{~m}^{2} / \mathrm{kg}$ to the hydration development was not quite significant due to the lower surface area of this latter $\left(400 \mathrm{~m}^{2} / \mathrm{kg}\right)$ compared to the surface area of Portland cement $\left(440 \mathrm{~m}^{2} / \mathrm{kg}\right)$.

The presence of slag with a fineness degree of $500 \mathrm{~m}^{2} / \mathrm{kg}$ in cementitious materials meanwhile, had a greater effect on the hydration reactions compared to the slag with a fineness degree of $400 \mathrm{~m}^{2} / \mathrm{kg}$. In fact, at all tested ages, the cement pastes containing slag with a fineness degree of $500 \mathrm{~m}^{2} / \mathrm{kg}$ showed a greater hydration degree as compared to the others cement pastes containing slag with a fineness degree of $400 \mathrm{~m}^{2} / \mathrm{kg}$ at the same replacement level. For instance, the 90 days hydration degree of P10BFS500 was higher by about $6 \%$ than that of P10BFS500. Similarly, the 90 days hydration degree of P40BFS500 was higher by about $5 \%$ than that of P40BFS400.

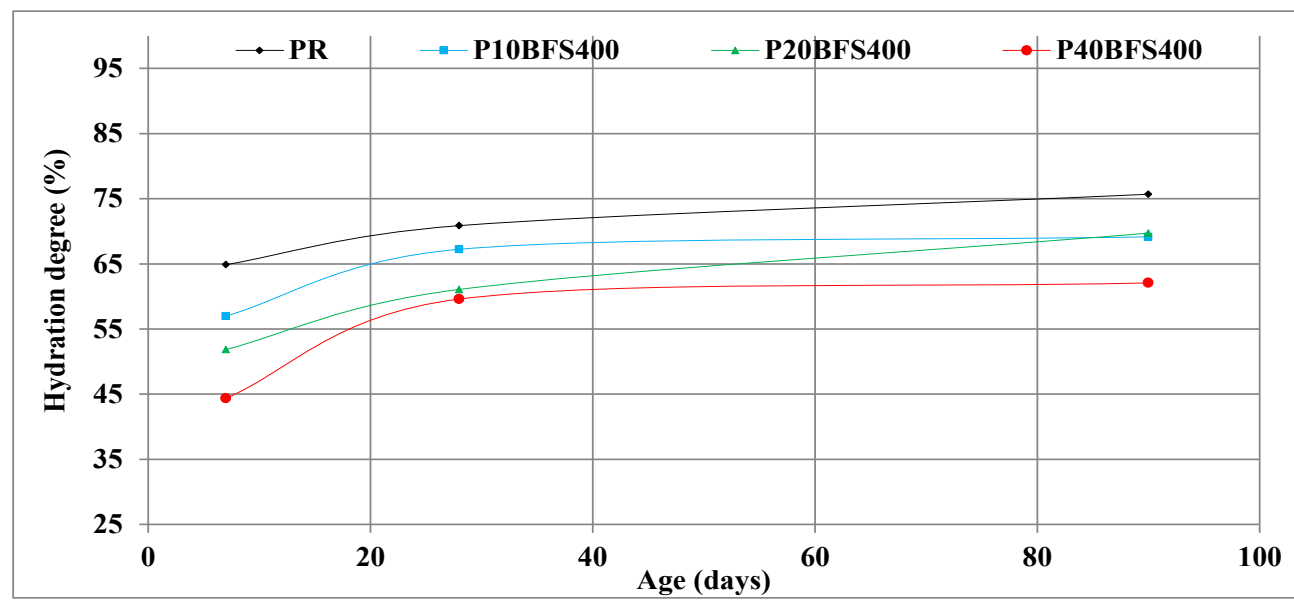

Fig.4. Hydration degree evolution for cement pastes containing BFS with fineness degree of $400 \mathrm{~m}^{2} /$ $\mathrm{kg}$.

From results presented in Fig.5, it was observed also that the difference in the hydration degree between the pure Portland cement paste and cement pastes prepared with slag decreased with increasing curing time and even, in the case of cement paste made with $10 \%$ of slag at a fineness degree of $500 \mathrm{~m}^{2} / \mathrm{kg}$, the 90 days hydration degree was similar to that of pure Portland cement paste. This enhancement in hydration degree could be attributed to the greater surface area of $500 \mathrm{~m}^{2} / \mathrm{kg}$ for slag compared to the $440 \mathrm{~m}^{2}$ for Portland cement where the slag particles can act as nucleation site for cement hydrates. Indeed, as reported for example by Berodier and Scrivener [13] and Cyr et al. [14], the heterogeneous nucleation effect is dependent on several factors such as the replacement level and the fineness of mineral additive. Berodier and Scrivener [4] found that a similar surface area for both cement and mineral additive is not efficient in the heterogeneous nucleation process. However, this effect is more remarkable for fine mineral additive particles.

The hydration degree of cement pastes containing slag agree well with the hydration heat evolution where both hydration degree and hydration heat released for cement pastes prepared with slag proportionally decreased with the increase in replacement level. This finding supports the hydration degree values accuracy calculated according to the modified TG method. 


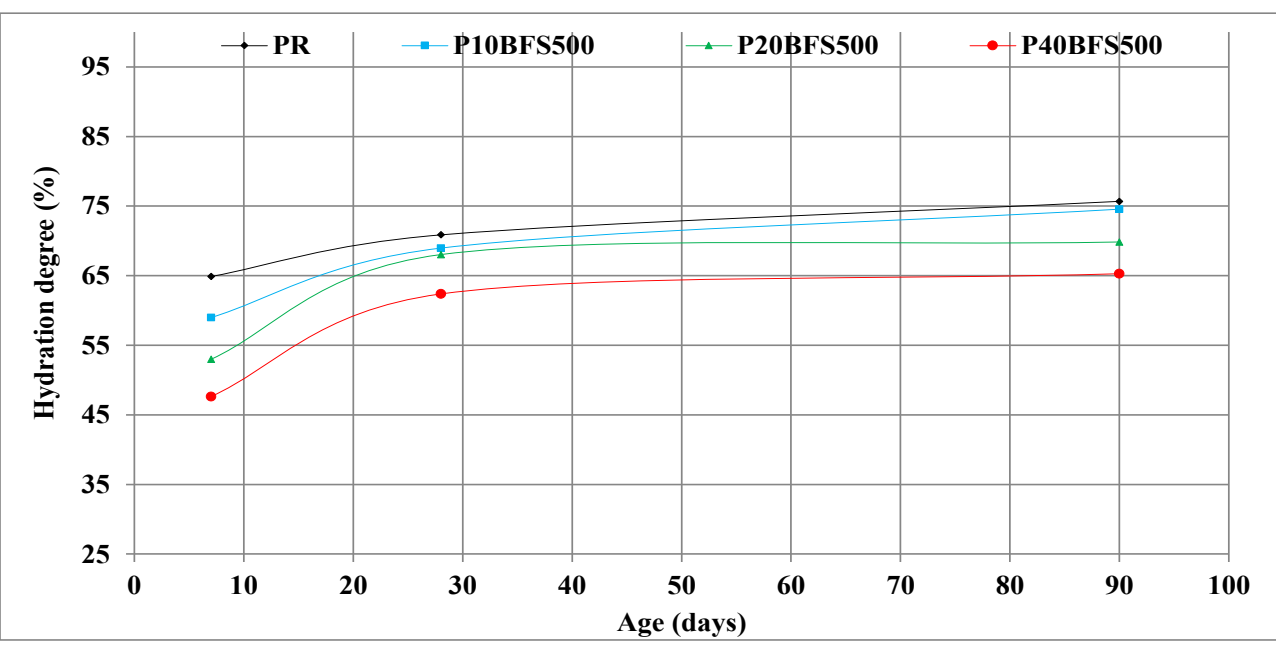

Fig.5. Hydration degree evolution for cement pastes containing BFS with fineness degree of 500 $\mathrm{m}^{2} / \mathrm{kg}$.

\section{Conclusions}

In this study, the impact of slag addition on hydration reactions in binary blended cement pastes was investigated. The hydration degree of these systems was estimated using modified TG method. The hydration degree values showed that the level of replacement and the fineness degree of slag conditioned the hydration degree of slag blended cement pastes. It was found that the increase in slag content caused a decrease in the hydration degree at all testing ages, due to dilution effect. It was observed meanwhile, that the increase in the fineness degree of slag stimulated the hydration reactions, which resulted in enhanced hydration degree.

\section{References}

1. D.M. Roy and G.M. Idorn, Amer. Concrt. Instit. J. 79, 444-457(1982)

2. W. Deboucha, N. leklou, A. Khelidj, M.N. Oudjit, Energ Proc. 139, 689- 695 (2017)

3. S.E. Chidiac and D.K Panesar (2008), Cem. Concr. Comp. 30, 63-71 (2008)

4. E. Berodier and K. Scrivener, Amer. Ceram. Soc. J. 97, 3764-3773 (2014)

5. M. Cyr, P. Lawrence, E. Ringot, Cem. Concr. Res. 36, 264-227(2006)

6. W. Deboucha, N. leklou, A. Khelidj, M.N. Oudjit, Constr. Build. Mater. 146, 687-701 (2017)

7. NF EN 197-1 (2000)

8. W. Deboucha, N. Leklou, A. Khelidj, KSCE J. Civ. Eng, 1-7 (2018)

9. EN NF 206-1 (2004)

10. H. Beushausen, M. Alexander, Y. Ballim, Constr. Build. Mater. 29, 533-540 (2012)

11. W. Deboucha, M. N. Oudjit, A. Bouzid, L. Belagraa, Proc. Eng. 108, 254 - 261 (2015)

12. P. Lawrence, M. Cyr, Cem. Concr. Res. 33, 1939-1947 (2003)

13. K.L. Scrivener, B. Lothenbach, N. De Belie, E. Gruyaert, J. Skibsted, R. Snellings, A. Vollpracht, Mater. Struct. 48, 835-862 (2015)

14. M. Cyr, P. Lawrence, E. Ringot, Cem. Concr. Res, 35, 719-730 (2005). 